\title{
Further Studies on the Causal Relationship between the Secretion of Estrogen and the Release of Luteinizing Hormone in the Rat
}

\author{
FUMIHIKO KOBAYASHI, KATSUMI HARA AND TAMOTSU MIYAKE \\ Shionogi Research Laboratory, Shionogi \& Co., Ltd., \\ Fukushima-ku, Osaka
}

\begin{abstract}
Synopsis
Further studies were made on the causal relationship between estrogen secretion and LH release by investigating the effects of exogenous estrogen on the progesteroneinduced delay in ovulation in the 4-day cyclic rats under the constant lighting regimen from 8 a.m. to 8 p.m. It was previously demonstrated that progesterone $(3 \mathrm{mg} / \mathrm{rat})$ administered during the period between the morning of the day before proestrus (diestrus II) and 2 a.m. proestrus caused an approximately 48-hr. delay in ovulation and that estrogen secreted till $4 \sim 7$ a.m. proestrus was necessary for ovulatory discharge of LH, which occurred between 5 and 7 p.m. proestrus under our lighting schedule. Estrogen administered between 3 and 5 p.m. on diestrus II completely restored ovulation, which was otherwise expected to delay by $48 \mathrm{hr}$. with progesterone given at 11 a.m. diestrus II. In the rats injected with progesterone at 2 a.m. proestrus and again with estrogen at 6 a.m. proestrus, ovulation occurred on the day expecting estrus, but did not occur in the rats receiving progesterone 8 p.m. or earlier in diestrus II followed by estrogen at 6 a.m. in proestrus. It is suggested, therefore, that the effect of integrated amount of estrogen from the afternoon of diestrus II until the morning of proestrus is responsible for the neural mechanism(s) to induce ovulatory discharge of LH in late proestrus.
\end{abstract}

The time sequence of various events occurring during estrous cycle in the rats under the controlled environmental conditions has been extensively studied (Everett, 1964 and 1969). Much of this work has been concerned with the events occurring during the "critical period" for release of luteinizing hormone (LH) on the afternoon of proestrus. Recently, evidences have been accumulated that the presence of ovaries on the day before proestrus is necessary for the occurrence of a series of phenomena including ovulatory discharge of gonadotropins (Schwartz, 1964; Lawton and Sawyer, 1968; Schwartz and Lawton, 1968; Brown-Grant, 1969).

Our previous work (Miyake, 1968; Hori et al., 1968; Kobayashi et al., 1968; Uchida et al., 1969) elucidated the chronologic relationship between the release of $\mathrm{LH}$ and secretion of

Received for publication September 7, 1969. ovarian steroids under our lighting schedule, and demonstrated that estrogen starting to increase on the afternoon of the day before proestrus (diestrus II) was responsible for the release of $\mathrm{LH}$ at proestrus in 4-day cyclic rats. This was supported by the fact that the delay in LH release and ovulation caused by progesterone administration at diestrus II, the treatment of which reduces or curtails estrogen secretion (Brown-Grant, 1969), can be restored by exogenous estrogen given at an appropriate time (Kobayashi et al., 1969a). It was further demonstrated by ovariectomy that the estrogen secreted during the period between the afternoon of diestrus II and the morning of proestrus was responsible for ovulatory discharge of LH in late proestrus (Kobayashi et al., 1969b). The present experiments have been conducted to know whether the effect of integrated amount of estrogen secreted from the afternoon of diestrus II till the morning of 
Table 1. Effect of estradiol-17 $\beta$ administered at varying times on diestrus II on the delayed ovulation induced by $3 \mathrm{mg}$ of progesterone given at $11 \mathrm{a} . \mathrm{m}$. diestrus II in the rat

\begin{tabular}{|c|c|c|c|}
\hline \multicolumn{2}{|c|}{ Treatment } & \multirow{3}{*}{$\begin{array}{c}\begin{array}{c}\text { No. of rats } \\
\text { ovulated }\end{array} \\
\text { No. of rats used }\end{array}$} & \multirow{3}{*}{$\begin{array}{l}\text { Aver. No. of ova } \\
\text { per rat }\end{array}$} \\
\hline \multirow{2}{*}{$\begin{array}{l}\text { Progesterone } \\
(3 \mathrm{mg} / \mathrm{rat})\end{array}$} & \multirow{2}{*}{$\begin{array}{l}\text { Estradiol-17 } \\
(200 \mu \mathrm{g} / \mathrm{rat})\end{array}$} & & \\
\hline & & & \\
\hline 11 a.m. & - & $0 / 5$ & 0 \\
\hline 11 a.m. & 7 a.m. & $0 / 5$ & 0 \\
\hline 11 a.m. & 9 a.m. & $0 / 5$ & 0 \\
\hline 11 a.m. & 11 a.m. & $0 / 5$ & 0 \\
\hline 11 a.m. & 2 p.m. & $2 / 5$ & 1.8 \\
\hline 11 a.m. & 3 p.m. & $4 / 5$ & 6.2 \\
\hline 11 a.m. & 4 p.m. & $4 / 5$ & 4.8 \\
\hline 11 a.m. & 5 p.m. & $7 / 10$ & 5.2 \\
\hline 11 a.m. & 6 p.m. & $1 / 7$ & 1.4 \\
\hline 11 a.m. & 7 p.m. & $2 / 7$ & 2.3 \\
\hline 11 a.m. & 8 p.m. & $1 / 5$ & 0.2 \\
\hline 11 a.m. & 9 p.m. & $0 / 5$ & 0 \\
\hline
\end{tabular}

* All animals were autopsied to inspect ovulation $48 \mathrm{hrs}$. after the injection of progesterone.

proestrus is necessary for the initiation of ovulatory discharge of LH or not.

\section{Materials and Methods}

Adult female rats of the Wistar strain weighing approximately $200 \mathrm{~g}$ were kept in an air-conditioned room with a controlled lighting regimen, $12 \mathrm{hr}$. light ( 8 a.m. $\sim 8$ p.m.) and 12 hr. darkness, and were used after having confirmed at least two consecutive 4-day estrous cycle. To investigate whether estrogen has a stimulative effect on LH release and ovulation, estradiol-17 $\beta$ was injected to the rats pretreated with progesterone for the induction of 48-hr. delay in LH release and ovulation (Kobayashi et al., 1969a). Each of the steroids was dissolved in sesame oil and injected subcutaneously at the dosage of $5 \mathrm{mg}$ per rat for progesterone and $0.2 \mathrm{mg}$ per rat for estradiol- $17 \beta$.

Experiment 1: Estradiol-17 $\beta$ was injected at various intervals before or after the treatment with progesterone at 11 a.m. on diestrus II. At autopsy on the morning of the day expecting estrus, the occurrence of ovulation, which is to be confirmed by the presence of ova in the dilated ampulla of the oviduct, was checked by the method described in the previous report (Kobayashi and Miyake, 1960).

Experiment 2: A single injection of progesterone was given initially to the rats at $2,8,11$ p.m. diestrus II or at 2 a.m. proestrus and an additional injection of estradiol-17 $\beta$ was given at 6 a.m. proestrus. The animals were autopsied on the day expecting estrus for the inspection of ovulation.

Experiment 3: A single injection of progesterone was given at 2 a.m. proestrus and an additional injection of estradiol- $17 \beta$ was given at $2,4,6$, or 9 a.m. proestrus. The presence of ova in the oviduct was inspected on the following morning.

\section{Results}

The restorative effect of estradiol given at varying times during diestrus II on the delayed ovulation induced by progesterone, which was administered at $11 \mathrm{a} . \mathrm{m}$. diestrus II, is presented in Table 1. The control rats receiving progesterone alone did not ovulate at all on the day expecting estrus. In the rats injected with estradiol at 3, 4 or 5 p.m. diestrus II, 4 to 6 hrs. after the progesterone pretreatment, high incidence of ovulation was observed on the day expecting estrus. However, when estradiol injection was delayed until 6 p.m. or later on diestrus II, incidence of ovulation decreased markedly and only 1 or 2 out of 5 or 7 rats ovulated. No ovulation was observed in the group receiving estradiol at 9 p.m. diestrus II. 
Table 2. Ovulation inducing activity of estrogen administered at 6 a.m. proestrus in the rats treated with progesterone at varying times between diestrus II and proestrus

\begin{tabular}{|c|c|c|c|}
\hline \multicolumn{2}{|c|}{ Treatment } & \multirow{3}{*}{$\begin{array}{c}\begin{array}{c}\text { No. of rats } \\
\text { ovulated* }\end{array} \\
\text { No. of rats used }\end{array}$} & \multirow{3}{*}{$\begin{array}{l}\text { Aver. No. of ova } \\
\text { per rat }\end{array}$} \\
\hline Progesterone & Estradiol-17 $\beta$ & & \\
\hline$(5 \mathrm{mg} / \mathrm{rat})$ & $(200 \mu \mathrm{g} / \mathrm{rat})$ & & \\
\hline D II, 2 p.m. & P, 6 a.m. & $0 / 5$ & 0 \\
\hline D II, 8 p.m. & P, 6 a.m. & $1 / 5$ & 2.0 \\
\hline D II, 11 p.m. & $\mathrm{P}, 6$ a.m. & $4 / 5$ & 5.8 \\
\hline $\mathrm{P}, \quad 2$ a.m. & P, 6 a.m. & $5 / 5$ & 7.6 \\
\hline
\end{tabular}

* All animals were autopsied on the following morning of estrogen injection.

$\mathrm{D}$ : diestrus

P : proestrus

The rats given estradiol simultaneously with or before progesterone injection did not show ovulation on the day expecting estrus. These results indicate that expecting delay in $\mathrm{LH}$ release and subsequent ovulation caused by progesterone treatment on diestrus II are completely restored only when estrogen is administered on the afternoon of the same day, before 5 p.m., which corresponds to the onset of critical period for ovulatory discharge of LH at proestrus under our lighting schedule in vivarium (Kobayashi et al., 1968).

To investigate whether estrogen secretion during the night between diestrus II and proestrus is necessary for $\mathrm{LH}$ release or not, the rats were given progesterone at varying times between the afternoon of diestrus II and early morning of proestrus and were additionally injected, at 6 a.m. proestrus, with estradiol which may act as a trigger for $\mathrm{LH}$ discharge, because estrogen secreted before 4 to 7 a.m. proestrus is indispensable for the ovulatory discharge of LH in late proestrus (Kobayashi et al., 1969b). The results are presented in Table 2. The rats pretreated with progesterone at 2 or 8 p.m. diestrus II had no or little ovulation on the day expecting estrus. On the contrary, ovulation was clearly observed on the day expecting estrus in 4 out of 5 rats receiving progesterone at 11 p.m. diestrus II and in all the rats given progesterone at 2 a.m. proestrus. Without estrogen administration at 6 a.m. proestrus, the treatment with progesterone in diestrus II and at 2 a.m. proestrus caused ovulation delay (Kobayashi et al., 1969a), which probably resulted from the suppression of further secretion of estrogen by progesterone (Kobayashi et al., 1969a; Brown-Grant, 1969). From these results, it is assumed that the endogenous estrogen secreted before 11 p.m. diestrus II or 2 a.m. proestrus at the latest is necessary for the release of $\mathrm{LH}$, which seems to be triggered by the additional estrogen secreted on the morning of proestrus.

In order to clarify the timing of triggering action of estrogen on the morning of proestrus, estradiol was administered subcutaneously at varying times on the morning of proestrus into the rats, the ovulation of which was expected to delay by the pretreatment with progesterone at 2 a.m. proestrus. The results are presented in Table 3. Nearly all the rats ovulated on the day expecting estrus regardless of the time of estrogen injection, which indicated that the neural mechanism(s) concerning LH release was sensitive for the triggering action of estrogen until 9 a.m. proestrus.

\section{Discussion}

The present study in the 4-day cyclic rats clearly demonstrates that estrogen given between 3 and 5 p.m. diestrus II restores ovulation, which is otherwise expected to delay by $48 \mathrm{hrs}$. with the injection of progesterone at 
Table 3. Ovulation inducing activity of estrogen administered at varying times of proestrous morning in the rats pretreated with progesterone at $2 \mathrm{a} . \mathrm{m}$. on the day of proestrus

\begin{tabular}{|c|c|c|c|}
\hline \multicolumn{2}{|c|}{ Treatment } & \multirow{3}{*}{$\begin{array}{c}\begin{array}{c}\text { No. of rats } \\
\text { ovulated }\end{array} \\
\text { No. of rats used }\end{array}$} & \multirow{3}{*}{$\begin{array}{c}\text { Aver. No. of ova } \\
\text { per rat }\end{array}$} \\
\hline \multirow{2}{*}{$\begin{array}{l}\text { Progesterone } \\
(5 \mathrm{mg} / \mathrm{rat})\end{array}$} & \multirow{2}{*}{$\begin{array}{c}\text { Estradiol-17 } \beta \\
(200 \mu \mathrm{g} / \mathrm{rat})\end{array}$} & & \\
\hline & & & \\
\hline 2 a.m. & - & $0 / 5$ & 0 \\
\hline 2 a.m. & 2 a.m. & $4 / 5$ & 10.2 \\
\hline 2 a.m. & 4 a.m. & $4 / 5$ & 7.4 \\
\hline 2 a.m. & 6 a.m. & $5 / 5$ & 7.6 \\
\hline 2 a.m. & 9 a.m. & $4 / 5$ & 8.0 \\
\hline
\end{tabular}

* All animals were autopsied on the following morning of estrogen injection.

11 a.m. diestrus II (Kobayashi et al., 1969a). This confirms our previous result that estrogen given 6 hr. (5 p.m.) after progesterone injection in diestrus II completely restored the 48-hr. delay in ovulation. The effectiveness of estrogen to restore the progesterone-induced delay in ovulation is only manifested when estrogen has been given before 5 p.m., but not at 6 p.m. or later, suggesting that an interaction in hypothalamo-pituitary-ovarian axis has a 24-hr. periodicity in its sensitivity. This may be concerned with the neural mechanism(s) of LH release (Everett and Sawyer, 1950; Lawton and Schwartz, 1968), because the estrogen-effective time in diestrus II for ovulation induction corresponds well with the time of the onset of ovulatory discharge of $\mathrm{LH}$ in the proestrous afternoon under our lighting schedule (Kobayashi et al., 1968).

A similar phenomenon was reported by Everett and Sawyer (1949), who claimed that the effectiveness of progesterone to facilitate ovulation by a single injection on the 3rd day of diestrus in 5-day cyclic rats was manifested only when the steroid had been administered before 2 p.m. but was ineffective when injected $3 \sim 4$ p.m. or later, the hour of which corresponds with the critical period for ovulatory discharge of $\mathrm{LH}$ in proestrus under their lighting schedule. Thus, the results in the present study suggest that, in normal cyclic rats, estrogen secretion should start to increase before 5 p.m. diestrus II for the occurrence of ovulatory discharge of LH in the next evening (proestrus). As demonstrated in the previous report (Kobayashi et al., 1969b), this initial secretion of estrogen on the afternoon of diestrus II before 5 to 7 p.m. also accounts for the cornification of vaginal smear on the day of estrus. The rats given estrogen simultaneously with or before the injection of progesterone at 11 a.m. diestrus II failed to ovulate on the day expecting estrus. The reason for this is not certain yet, but it may be the insensitivity of CNS to the action of estrogen in the morning and a remarkable increase in CNS sensitivity to estrogen on the afternoon of diestrus II.

Our previous experiment (Kobayashi et al., 1969b) demonstrated that the estrogen secreted between 4 and 7 a.m. proestrus acts as a trigger for the ovulatory discharge of LH. Progesterone administered to the 4-day cyclic rats at 11 p.m. diestrus II or at 2 a.m. proestrus inhibits spontaneous ovulation (Kobayashi et al., 1969a). When an additional injection of estrogen is given at 6 a.m. proestrus as a trigger for $\mathrm{LH}$ release, ovulation occurs normally on the day expecting estrus. However, the rats receiving progesterone at 2 or 8 p.m. diestrus II do not ovulate at all on the day expecting estrus in spite of the injection of estrogen at 6 a.m. proestrus. These results indicate that the secretion of estrogen until $2 \mathrm{a}$.m. proestrus at the latest is indispensable for the ovulatory discharge of LH on the afternoon of the same day, because the injection of progesterone reduces estrogen secretion (Brown-Grant, 1969) and induces the delay in $\mathrm{LH}$ release and ovulation 


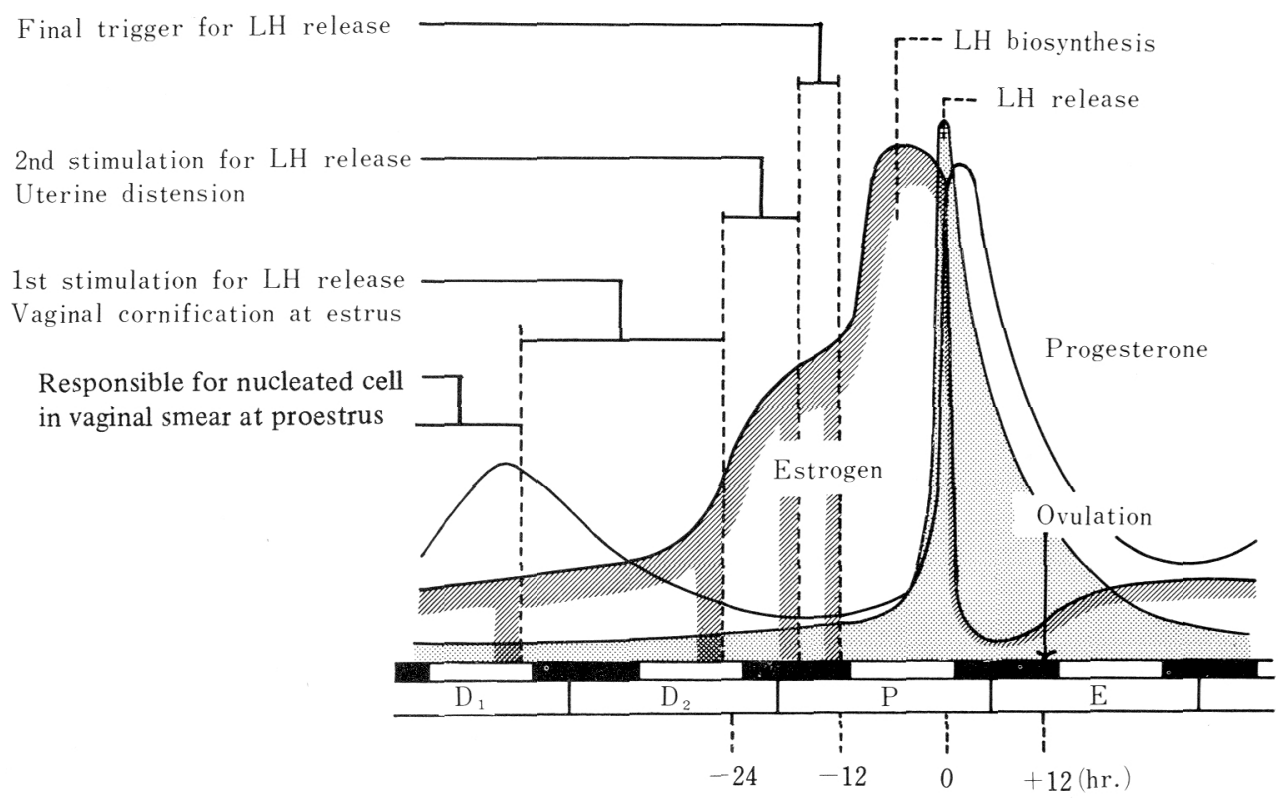

Fig. 1. Regulatory effect of estrogen on LH release in normal estrous cycle of the rat. (Schema)

when administered before 2 a.m. proestrus (Kobayashi et al., 1969a). Complete uterine distension was observed at proestrus in the rats ovariectomized at $4 \mathrm{a} . \mathrm{m}$. or later on proestrus in our previous experiment (Kobayashi et al., 1969b), indicating that estrogen secreting until around 2 a.m. proestrus is indispensable for either uterine distension or ovulatory discharge of LH in proestrus, for the later of which additional estrogen is necessary as a trigger on the early morning of proestrus as mentioned above.

A causal relationship between estrogen secretion and LH release assumed from the results of the present study together with those of the previous report (Kobayashi et al., 1969b) is schematically illustrated in Figure 1. Although estrogen secretion is increased rapidly from the afternoon of the day before proestrus until the critical period for $\mathrm{LH}$ release in proestrus, the total amount of estrogen secreted has no bearing on the initiation of $\mathrm{LH}$ release. As previously demonstrated (Kobayashi et al., 1969b), estrogen secreted until the morning of pro- estrus, the time of which is approximately 12 hrs. before the critical period for LH release, is responsible for the initiation of ovulatory discharge of LH. In this study, it is demonstrated that the secretion of this indispensable estrogen for $\mathrm{LH}$ release is completed in three consecutive phases; the first phase is the one in which estrogen is secreted till approximately $24 \mathrm{hr}$. before the critical period for $\mathrm{LH}$ release in proestrus and responsible for cornification of vaginal smear; the second phase is the one in which estrogen is secreted progressively till around 2 a.m. proestrus and induces uterine distension on proestrus; and the third phase is the one in which increased secretion of estrogen occurs between 4 and 7 a.m. on the morning of proestrus, which probably acts as a trigger for LH release. It is concluded, therefore, that the effect of integrated amount of estrogen from the afternoon of diestrus II till the morning of proestrus is responsible for the neural mechanism(s) to induce ovulatory discharge of LH in late proestrus. 


\section{References}

Brown-Grant, K., (1969). J. Endocrinol. 43, 539.

Everett, J. W. (1964). Physiol. Rev. 44, 373.

Everett, J. W. (1969). Ann. Rev. Physiol. 31, 383.

Everett, J. W. and C. H. Sawyer (1949). Endocrinology 45, 581.

Everett, J. W. and C. H. Sawyer (1950). Ibid. 47, 198.

Hori, T., M. Ide and T. Miyake (1968). Endocrinol. Japon. 15, 215.

Kobayashi, F. and T. Miyake (1960). Ann. Rept. Shionogi Res. Lab. 10, 213.

Kobayashi, F., K. Hara and T. Miyake (1968). Endocrinol. Japon. 15, 313.

Kobayashi, F., K. Hara and T. Miyake (1969a). Ibid. 16, 251.

Kobayashi, F., K. Hara and T. Miyake (1969b). Ibid. 16, 261.

Lawton, I. E. and C. H. Sawyer (1968). Endo- crinology 82, 831.

Lawton, I. E. and N. B. Schwartz (1968). Am. J. Physiol. 214, 213.

Miyake, T. Integrative Mechanism of Neuroendocrine System. Hokkaido University Medical Library Series, Vol. 1 (Itoh, S. ed.), p. 139 (1968).

Schwartz, N. B. (1964). Am. J. Physiol. 207, 1251.

Schwartz, N. B. and I. E. Lawton (1968). Neuroendocrinology 3, 9.

Uchida, K., M. Kadowaki and T. Miyake (1969). Endocrinol. Japon. 16, 227.

Addendum: The following sentence in Synopsis (line 9) of our previous report (1969b), "It was demonstrated that the ovary must be in situ between 4 a.m. and 7 a.m. at proestrus for the discharge of LH", should be corrected to "It was demonstrated that the ovary must be in situ until the time 4 to 7 a.m. at proestrus for the discharge of LH". 